\title{
Incidence and survival differences of differentiated thyroid cancer among younger women
}

This article was published in the following Dove Press journal:

Clinical Oncology in Adolescents and Young Adults

II November 2013

Number of times this article has been viewed

\section{Melissa M Boltz' \\ Laura M Enomoto',2 \\ Rollyn M Ornstein ${ }^{3}$ \\ Brian D Saunders ${ }^{1,4}$ \\ Christopher S \\ Hollenbeak ${ }^{1,2,5}$}

'Department of Surgery, ${ }^{2}$ Division of Outcomes Research and Quality, The Pennsylvania State University, College of Medicine, ${ }^{3}$ Department of Pediatrics, Division of Adolescent Medicine and Eating Disorders, The Pennsylvania State University, Hershey Children's Hospital, ${ }^{4}$ Division of General Surgery Specialties and Surgical Oncology, ${ }^{5}$ Department of Public Health Sciences, The Pennsylvania State University, College of Medicine, Hershey, PA, USA
Correspondence: Christopher S Hollenbeak Department of Surgery, The Pennsylvania State University, College of Medicine, 500 University Drive, HI5I, Hershey, PA I7033, USA

$\mathrm{Tel}+|7| 753 \mid 5890$

Fax + I $71753 \mid 4464$

Email chollenbeak@psu.edu
Abstract: Differentiated thyroid cancer is the most common endocrine malignancy, with an estimated 60,220 new cases diagnosed in the United States in 2013. For reasons that are unclear, differentiated thyroid cancer is three times more common in females than in males. However, among adolescent and young adult females between ages 15-39 years, differentiated thyroid cancer remains under-recognized. The disparity in cancer incidence and outcomes in this population may be secondary to the tumor's biology, and risk factors unique to women. This review summarizes the incidence and survival rates of thyroid cancer in women younger than 45 years of age, as well as the pathophysiology, etiology, risk factors, prognosis, and current and emerging treatment options for this patient population.

Keywords: differentiated thyroid cancer, young adult women, adolescents, incidence, risk factors, treatment

\section{Introduction}

Differentiated thyroid cancer (DTC) is the most common endocrine malignancy, with an estimated 60,220 new cases diagnosed in the United States (US) in 2013. ${ }^{1,2}$ For reasons that are unclear, thyroid cancer is two to three times more common in females than in males. Its prevalence continues to rise; in 2008, it became the sixth most diagnosed cancer in women. ${ }^{2}$ Although the peak incidence of DTC is diagnosed in women aged 45-49 years, and men aged 65-69 years, it does affect younger people. DTC accounts for approximately $10 \%$ of malignancies diagnosed in persons aged $15-29$ years. $^{3}$

In the US, DTC incidence has risen steadily for decades, increasing by $74 \%$ from 1976 to 2005 . This rise has been limited to the papillary histologic subtype. ${ }^{4}$ It has been reported by Davies et al that, in the US, the increase is due to increased diagnosis and detection of small, impalpable, subclinical tumors. ${ }^{5}$ A more recent study investigated trends in DTC in the adult population between 1988-2005, and determined that increased detection could not be the only factor underlying increased incidence of larger cancers. The authors advocated for research to identify environmental, dietary, and genetic risk factors responsible for the increase. ${ }^{6}$ However, among adolescent and young adult females between ages 15-39 years, thyroid cancer remains underrecognized. The disparity in cancer incidence and outcomes in this population may be secondary to the tumor's biology, and risk factors unique to women. ${ }^{4}$

The purpose of this review is to summarize the incidence and survival rates of thyroid cancer in women younger than 45 years of age, as well as the pathophysiology, etiology, risk factors, prognosis, and current and emerging treatment options for this patient population. 


\section{Incidence and epidemiology in younger women}

Thyroid carcinoma represents $4 \%$ of all cancers in women in the US, and it is the sixth most frequently diagnosed cancer in females. ${ }^{2}$ In women aged 20-29 years, the thyroid is the most common cancer site. ${ }^{7}$ DTC, including papillary thyroid carcinoma (PTC), follicular thyroid carcinoma (FTC), and their variants, is by far the most common type of thyroid malignancy in this age group, representing 95\% of thyroid cancers. The remainder consists of medullary thyroid carcinoma (MTC) and anaplastic (undifferentiated) thyroid carcinomas (ATCs). Of patients diagnosed between 1988-2001, $96 \%$ of ATC diagnoses were made in patients 45 years of age and older. ${ }^{8}$ Given the rarity of ATC in the $20-39$ year-old population, it will not be discussed in this article.

According to Surveillance, Epidemiology, and End Results (SEER) data from 1973-2009, the median age at diagnosis of thyroid cancer was 45 years, in women. ${ }^{7}$ Among women diagnosed with PTC, $2.7 \%$ were diagnosed at an age younger than 20 years, $25.1 \%$ were diagnosed at between $20-34$ years old, $24.0 \%$ between $35-44$ years, $21.5 \%$ between 45-54 years, and 26.7\% at older than 54 years. Over one third of women with FTC were older than 54 years at diagnosis. The majority of women diagnosed with PTC and FTC were white; $64.6 \%$ and 56.2\% were localized PTC and FTC, respectively. For both PTC and FTC, the majority of tumors were less than 1.0 centimeter in size (Table 1). ${ }^{7}$

Age-adjusted incidence rates standardized to the 2000 US population demonstrated a nearly five-fold increase in incidence of PTC in the past 35 years, rising from 4 cases per 100,000 person-years, in 1973 , to 19 cases per 100,000 person-years, in $2009 .^{7}$ A similar trend was not seen in FTC, which has remained stable at approximately 1 case per 100,000 person-years (Figure 1). When stratified into age groups $(<20,20-34,35-44,45-54$, and $>54$ years), the age-adjusted incidence rate of PTC in women less than 20 years of age remained low. However, in women age 20 and older, the incidence has increased dramatically over time by four- to five-fold (Figure 2). Age-adjusted incidence of FTC remained stable, and, similarly to PTC, it had a lower incidence in women younger than 20 years old.

When stratified by race/ethnicity (white, black, and other), all races demonstrated an increase in incidence of PTC over time, but the age-adjusted incidence of PTC in white women was more than twice that of women of black or other races (Figure 3). In 2009, the incidence in white women was 20 cases per 100,000 person-years, compared with 11 cases per 100,000 person-years in black women.
Table I Summary statistics of patients with papillary and follicular thyroid carcinoma recorded in SEER from 1973-2009

\begin{tabular}{|c|c|c|c|}
\hline \multirow[t]{2}{*}{ Variable } & \multirow{2}{*}{$\begin{array}{l}\text { Papillary } \\
(n=37,940)\end{array}$} & \multirow{2}{*}{$\begin{array}{l}\text { Follicular } \\
(n=5,291)\end{array}$} & \multirow[t]{2}{*}{$P$-value } \\
\hline & & & \\
\hline Age & & & $<0.0001$ \\
\hline$<20$ & $2.7 \%$ & $2.3 \%$ & \\
\hline $20-34$ & $25.1 \%$ & $20.0 \%$ & \\
\hline $35-44$ & $24.0 \%$ & $19.0 \%$ & \\
\hline $45-54$ & $21.5 \%$ & $19.5 \%$ & \\
\hline$>54$ & $26.7 \%$ & $39.3 \%$ & \\
\hline Race & & & $<0.000$ I \\
\hline White & $82.3 \%$ & $79.0 \%$ & \\
\hline Black & $5.4 \%$ & $9.9 \%$ & \\
\hline Asian/Pacific Islander & $9.5 \%$ & $8.2 \%$ & \\
\hline Other & $1.2 \%$ & $1.2 \%$ & \\
\hline Unknown & $1.6 \%$ & $1.7 \%$ & \\
\hline SEER summary stage & & & $<0.0001$ \\
\hline Localized & $64.6 \%$ & $56.2 \%$ & \\
\hline Regional & $30.5 \%$ & $34.3 \%$ & \\
\hline Distant & $2.9 \%$ & $6.0 \%$ & \\
\hline Unstaged & $2.0 \%$ & $3.5 \%$ & \\
\hline Tumor size & & & $<0.0001$ \\
\hline$<1.0 \mathrm{~cm}$ & $34.7 \%$ & $22.4 \%$ & \\
\hline $1.0-3.9 \mathrm{~cm}$ & $0.1 \%$ & $0.1 \%$ & \\
\hline$\geq 4.0 \mathrm{~cm}$ & $0.0 \%$ & $0.0 \%$ & \\
\hline No tumor & $0.1 \%$ & $0.1 \%$ & \\
\hline Unknown & $65.1 \%$ & $77.4 \%$ & \\
\hline
\end{tabular}

Note: Data from SEER. ${ }^{\text {? }}$

Abbreviation: SEER, Surveillance, Epidemiology, and End Results database.

Age-adjusted incidence of FTC did not demonstrate notable racial differences, with white and black women having only slightly higher incidences of FTC than women of other races.

Age-adjusted incidence rates of local PTC have increased from 2 cases per 100,000 person-years, in 1973, to over 12 cases per 100,000 person-years, in 2009 (Figure 4). Rates of regional disease have also risen, demonstrating a five-fold increase over 35 years. Distant PTC incidence rates have remained relatively low over time. Local, regional, and distant FTC age-adjusted incidence rates have been consistently low over time, with less than 1 case per 100,000 person-years, for all stages.

From an international perspective, the age-adjusted incidence rates of DTC in females aged 0-14 years in Great Britain increased from 0.3 to 0.5 . The incidence rates for females aged 15-29 and 30-49 increased from 6.9 to 12.4, and from 21.2 to 42.3 , respectively. ${ }^{9}$ In Italy, the age-adjusted incidence rates for women age $<85$ years ranged from 3.5 to 8.5 from 1991-1995, and increased by 7.3 to 37.5 from 2001-2005. ${ }^{10}$

There are large survival differences between women younger than 45 years of age and women age 45 and older. Kaplan-Meier survival analysis demonstrated a greater 


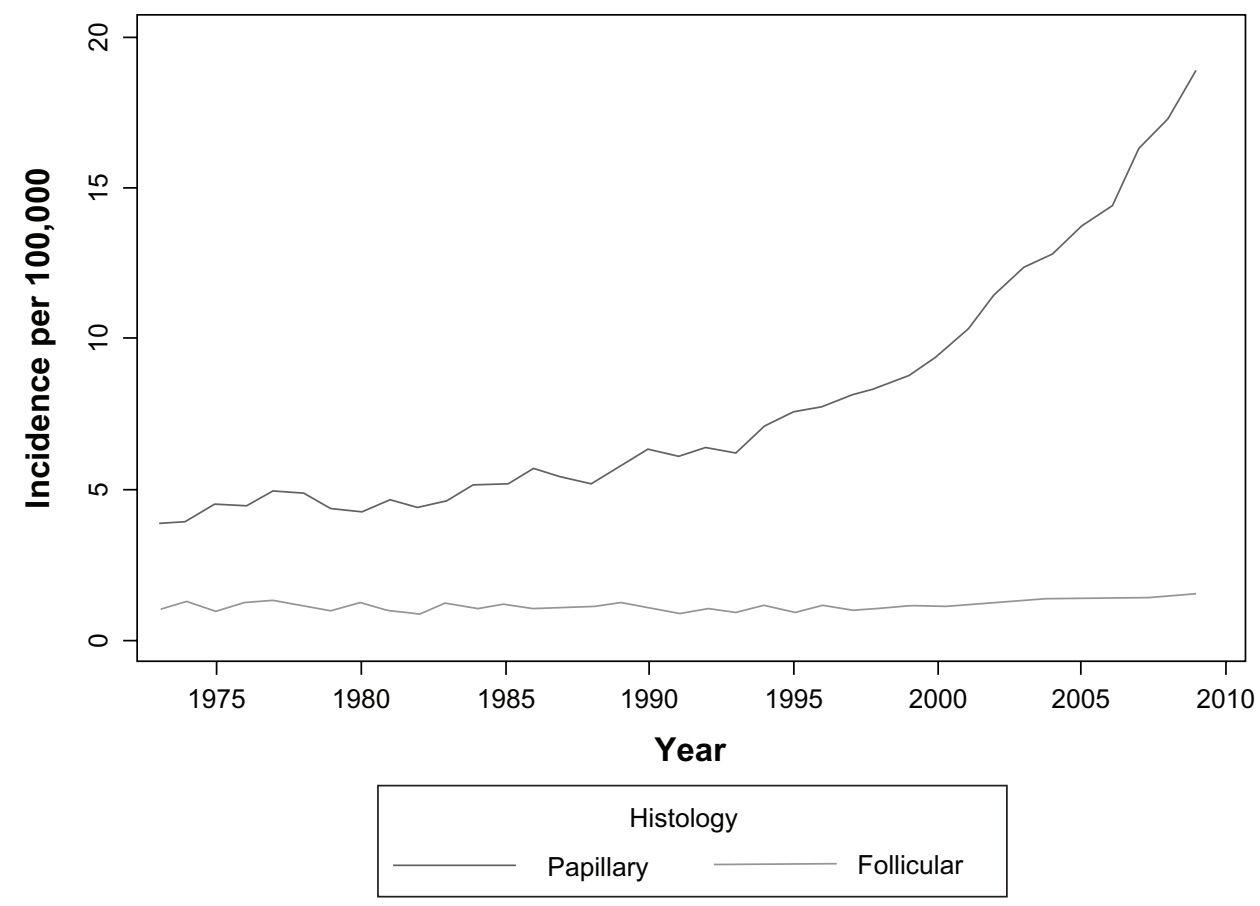

Figure I Age-adjusted incidence rates of thyroid carcinoma, stratified by histology.

than $75 \%$ survival probability at 400 months for women younger than 45 years who are diagnosed with PTC or FTC, compared with women age 45 and older, whose survival probability at 400 months was less than 25\% (Figure 5). Kaplan-Meier analysis also demonstrated similar age-dependent survival probabilities, when stratified by stage of disease (Figure 6). Women younger than 45 years of age who were diagnosed with PTC or FTC had greater than $75 \%$ survival probability at 400 months, regardless of stage. However, in women older than 45 years, survival
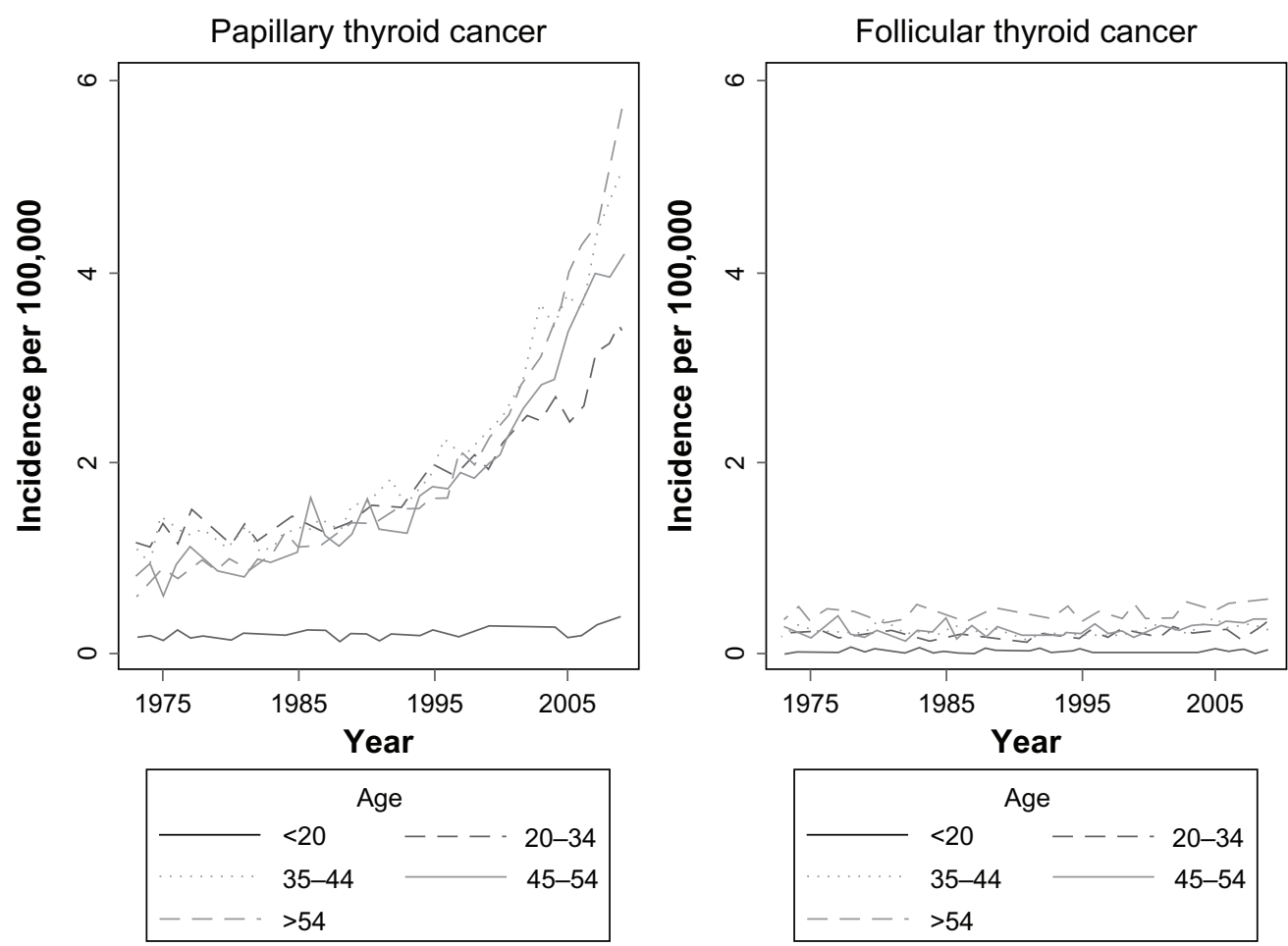

Figure 2 Age-adjusted incidence rates of papillary and follicular thyroid carcinoma, stratified by age. 

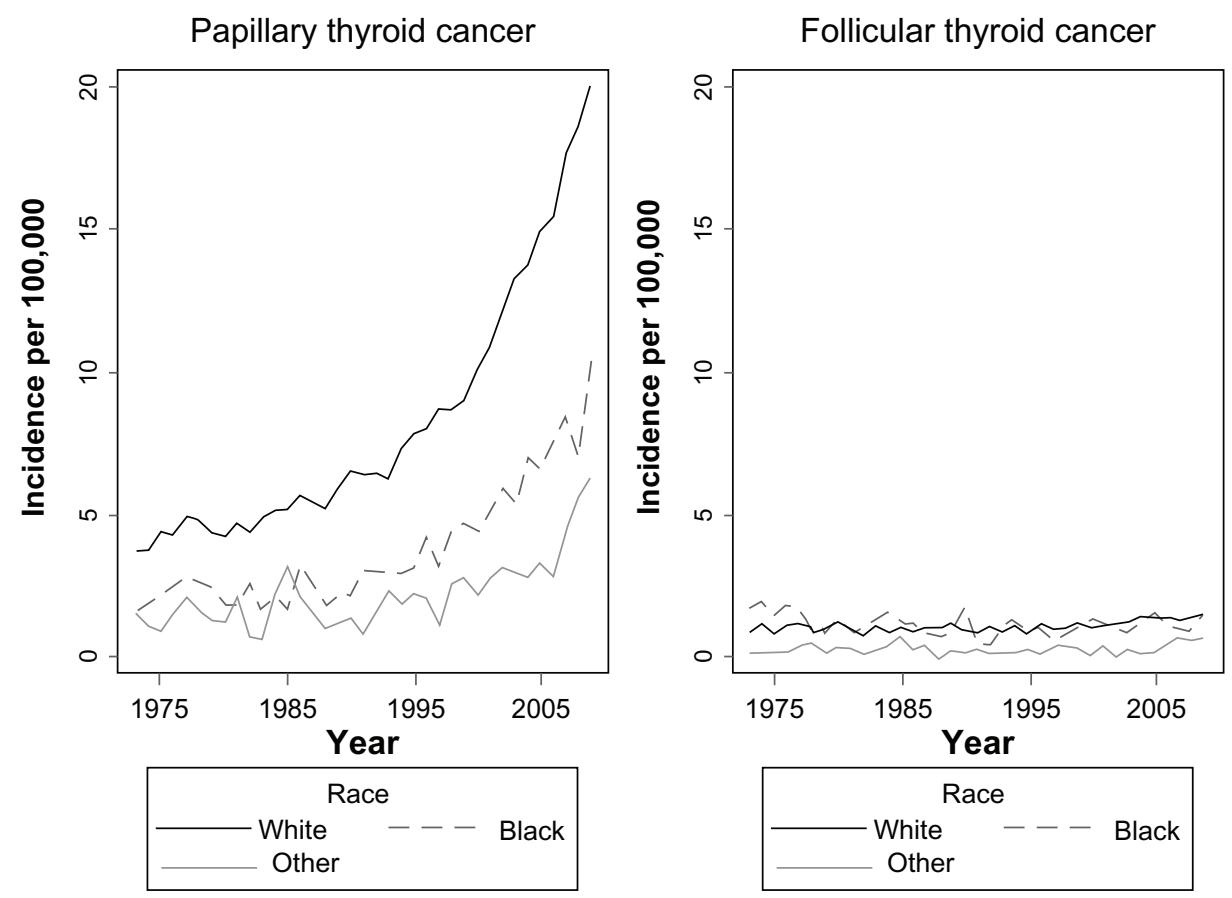

Figure 3 Age-adjusted incidence rates of papillary and follicular thyroid carcinoma, stratified by race.

probabilities dropped precipitously, for all stages, with less than $25 \%$ survival probability at 400 months.

Multivariate Cox proportional hazards modeling, performed to estimate the risk of death from thyroid cancer, after controlling for other potential confounders, suggested several significant factors. After controlling for other covariates, women aged 35-44 had more than three times the likelihood of death, compared with women younger than 20 years old (Hazard Ratio [HR]: 3.08; 95\% Confidence Interval [CI]: 2.12-4.41) (Table 2). Black women had a significantly higher
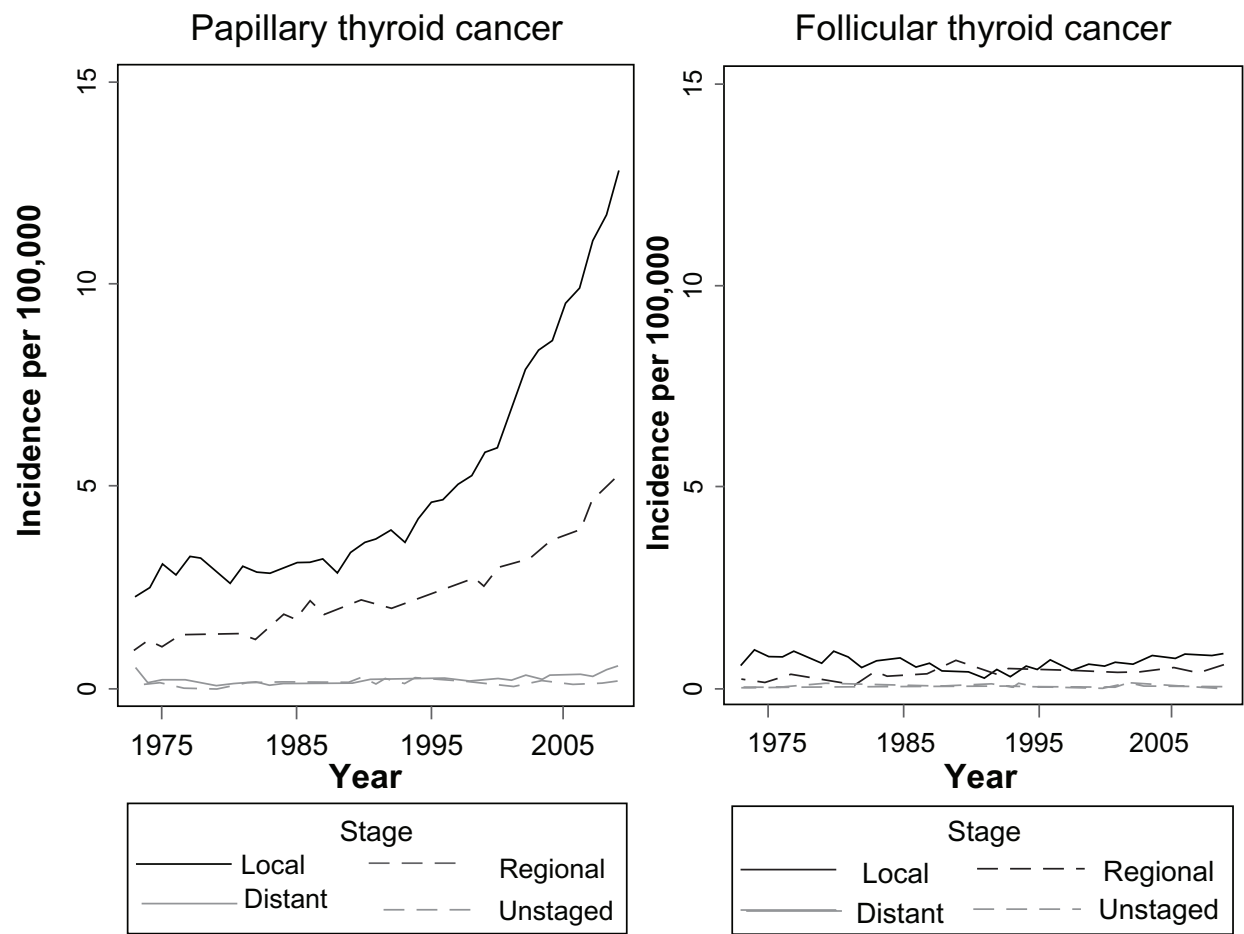

Figure 4 Age-adjusted incidence rates of papillary and follicular thyroid carcinoma, stratified by stage. 

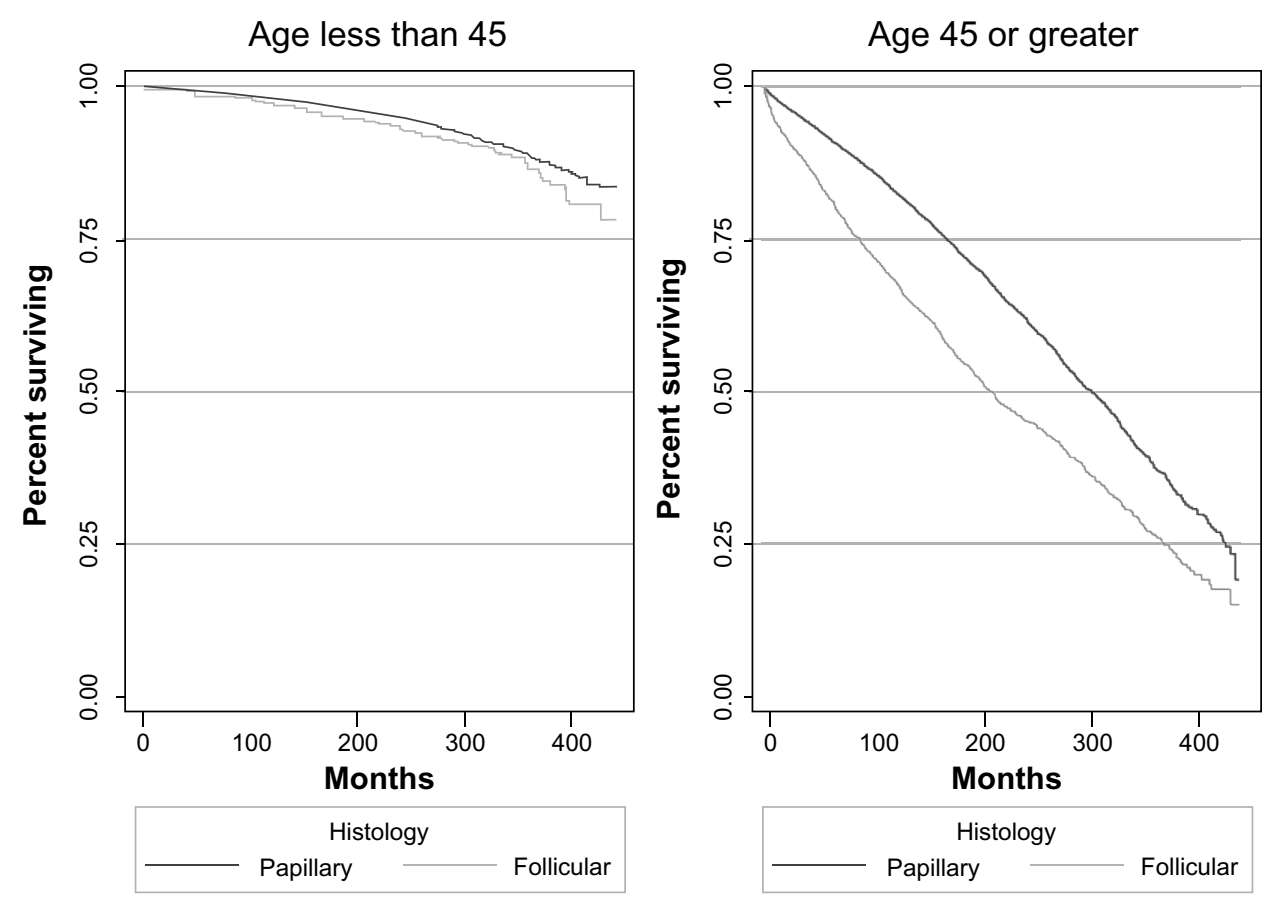

Figure 5 Kaplan-Meier survival curves for papillary thyroid carcinoma and follicular thyroid carcinoma, stratified by age.

risk of death, compared with white women (HR: 1.83; 95\%

CI: 1.44-2.33), and women with distant disease had more than twice the risk of death than women with local occurrence (HR: 2.60, 95\% CI: 1.92-3.53). Women with FTC were at slightly higher risk than women with PTC, but this difference was not significant (HR: 1.19, 95\% CI: 0.99-1.43).

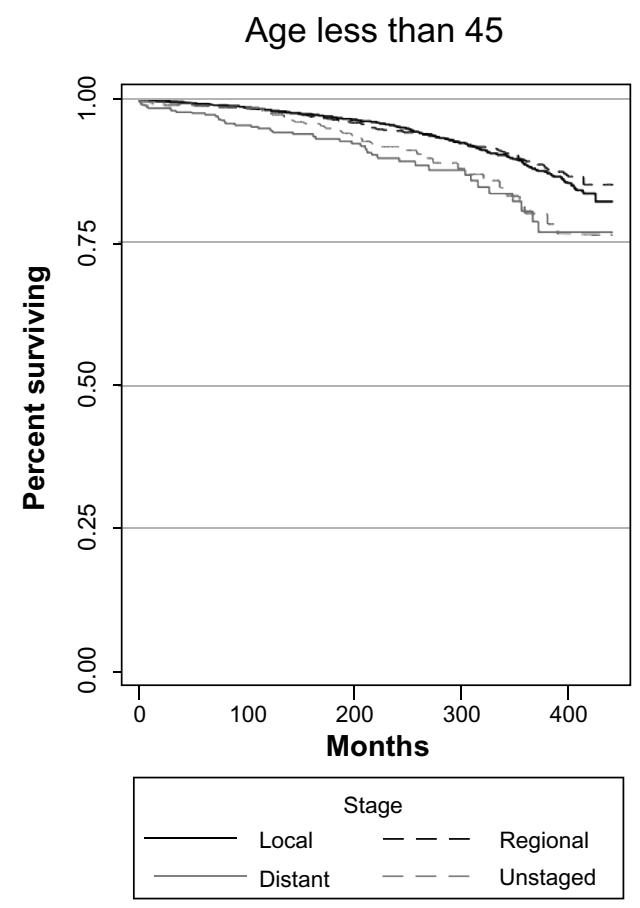

\section{Pathophysiology and etiology}

DTC arises from the thyroid follicular epithelium. The diagnosis of PTC and FTC is based on unique histologic features, with subtypes of each. In PTC, these include follicular cell, tall cell, columnar cell, diffuse sclerosing, and encapsulated variants; included in FTC are Hurthle cell, clear cell, and

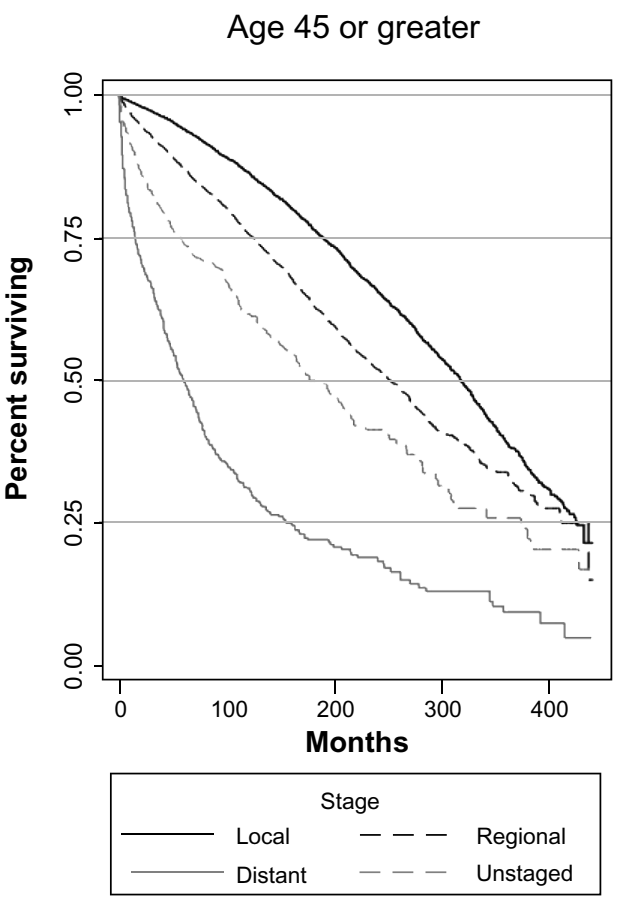

Figure 6 Kaplan-Meier survival curves for papillary thyroid carcinoma, stratified by stage and age. 
Table 2 Results of Cox proportional hazards regression model in women younger than age 45

\begin{tabular}{|c|c|c|c|c|}
\hline \multirow[t]{2}{*}{ Variable } & \multirow[t]{2}{*}{$\begin{array}{l}\text { Hazard } \\
\text { ratio }\end{array}$} & \multicolumn{2}{|c|}{$\begin{array}{l}95 \% \text { confidence } \\
\text { interval } \\
\end{array}$} & \multirow[t]{2}{*}{$P$-value } \\
\hline & & Lower & Upper & \\
\hline \multicolumn{5}{|l|}{ Age } \\
\hline$<20$ & Reference & & & \\
\hline $20-34$ & 1.28 & 0.89 & 1.84 & 0.18 \\
\hline $35-44$ & 3.08 & 2.15 & 4.41 & $<0.0001$ \\
\hline \multicolumn{5}{|l|}{ Race } \\
\hline White & Reference & & & \\
\hline Black & 1.83 & $\mathrm{I} .44$ & 2.33 & $<0.0001$ \\
\hline Asian/Pacific Islander & 1.19 & 0.94 & $1.5 \mid$ & 0.15 \\
\hline Other & 1.94 & 1.28 & 2.94 & 0.00 \\
\hline Unknown & 0.69 & 0.34 & 1.39 & 0.30 \\
\hline \multicolumn{5}{|l|}{ Histology } \\
\hline Papillary & Reference & & & \\
\hline Follicular & 1.19 & 0.99 & 1.43 & 0.07 \\
\hline \multicolumn{5}{|l|}{ SEER summary stage } \\
\hline Localized & Reference & & & \\
\hline Regional & I.II & 0.96 & 1.29 & 0.17 \\
\hline Distant & 2.60 & 1.92 & 3.53 & $<0.0001$ \\
\hline Unstaged & 1.98 & 1.44 & 2.73 & $<0.0001$ \\
\hline \multicolumn{5}{|l|}{ Decade } \\
\hline $1973-1979$ & Reference & & & \\
\hline 1980-1989 & 0.88 & 0.74 & 1.05 & 0.16 \\
\hline $1990-1999$ & 0.72 & 0.58 & 0.90 & 0.00 \\
\hline 2000-2009 & 0.75 & 0.56 & 1.02 & 0.07 \\
\hline
\end{tabular}

Abbreviation: SEER, Surveillance, Epidemiology, and End Results database.

insular carcinoma. The follicular and diffuse sclerosing variants of PTC are more common in children and young adults, compared with older individuals. ${ }^{8}$

Research has turned toward seeking a better understanding of the molecular and genetic basis of DTC. It is now recognized that activation of the mitogen-activated protein kinase (MAPK) signaling pathway is critical in tumorigenesis. ${ }^{11,12}$ More than $70 \%$ of PTCs are due to genetic events in the $R A S$, $B R A F$, or RET proto-oncogenes. One of the major events associated with the development of PTC, specifically in younger adults, is a chromosomal rearrangement that links the promoter region of an unrelated gene to the carboxyl terminus of the RET (rearranged during transfection) proto-oncogene. ${ }^{8,13}$ This rearrangement produces a chimeric oncogene, resulting in a constitutively activated form of the RET receptor tyrosine kinase (not typically expressed in thyroid follicular cells), thereby promoting tumorigenesis.

Mutations in BRAF are the most common cause of PTC, and occur in $36 \%-83 \%$ of cases. PTCs that are positive for a $B R A F$ mutation are also more clinically aggressive. ${ }^{11}$ Other genes and gene products involved in PTC include $R A S$, the $T R K$ proto-oncogene. FTCs have been associated with Pax8$P P A R \gamma$ translocations, and PI3KCA genes.
Approximately 5\% of patients with PTC have a family history of the disease. ${ }^{8,14}$ Patients with familial non-medullary thyroid cancer may have poorer prognoses, given that these cases have a more aggressive course and shorter diseasefree intervals after treatment. ${ }^{15,16}$ Other genetic syndromes in which there is an increased risk of DTC include familial adenomatous polyposis (APC gene), Cowden syndrome (PTEN gene), and Werner syndrome (RECQL2 gene). ${ }^{8,14}$ PTC identified in familial adenomatous polyposis is usually a rare variant. If it is identified, especially in young adult women, the subsequent risk for colonic neoplasia should be considered. ${ }^{8}$

In 2006, the US National Cancer Institute initiated a Progress Review Group on Adolescent and Young Adult (AYA) Oncology to investigate a potential biological basis for age-related differences in outcomes for AYAs with cancer. ${ }^{17}$ A study by Vriens et al compared the clinical and molecular features of PTC in AYAs with patients over 40 years of age. The results indicated that AYA patients with PTC had a different extent of disease at presentation, and had better outcomes, compared with older patients. The authors identified several genes (ECM1, ERBB2, UPA, PFKFB2, and MEIS2) that were expressed differently between the AYA group and the group aged $>40$ years. ${ }^{18}$ These findings suggest a possible molecular basis for differences in the extent of disease at presentation, and for the differences in outcomes observed with adolescents and young adults.

\section{Risk factors and prognosis}

The major risk factor for development of DTC, and PTC, in particular, is exposure of the head and neck to radiation during childhood. ${ }^{7}$ Most cases of radiation-induced PTC in the 21 st Century are secondary to therapeutic radiation, used to treat a prior malignancy. Although the data are conflicting, it appears that radiation-induced thyroid cancers are not significantly different in clinical behavior from sporadic, non-radiation-induced tumors. ${ }^{8}$ The latency period for developing DTC after radiation exposure is highly variable, and is dependent upon age and amount of exposure. A study by Kikuchi et al retrospectively analyzed 171 patients who had a history of exposure to radiation and were treated surgically at University of California, San Francisco-affiliated hospitals for thyroid neoplasms between 1960-1999. The mean latency periods for follicular and papillary thyroid carcinomas were 20.5 years and 34 years, respectively. ${ }^{19}$

Exposure to ionizing radiation, such as radioactive iodine (RAI), from the large environmental Chernobyl nuclear accident in 1986, is another documented risk for the development 
of PTC. ${ }^{8}$ Doses of RAI used in the treatment of hyperthyroidism, and routine diagnostic studies, fortunately appear to be below the threshold for tumorigenesis. ${ }^{8}$

The markedly higher rates of DTC in young women, compared against men, suggest that sex steroid hormones may be involved in the development of the disease. A study by Horn-Ross et al investigated the effects of menstrual, reproductive, and other hormonal factors on PTC risk. ${ }^{20} \mathrm{An}$ increased risk was found among the 117,646 women examined who were less than 45 years old and had a later age of menarche (mean or average age: 14 years). Risk was also increased among young women who had longer adolescent menstrual cycles ( $>30$ days), and whose last pregnancy had ended within 5 years of enrollment in the study. ${ }^{20}$

Additionally, an international pooled analysis of 14 case-control studies, with data from 1,800 women with PTC, observed that aspects of pubertal development and parity, particularly among women younger than 45 years, increased a woman's risk of developing thyroid cancer. ${ }^{21} \mathrm{In}$ this analysis, weak associations were observed between increased DTC risk and later age at menarche, having had a miscarriage, and having had a full-term pregnancy; but no association was observed for age at first and last birth. Other recent studies have suggested that the critical aspect of parity could be an elevation in risk during the 5 years following pregnancy. ${ }^{20}$ Later age at menarche has been associated with irregular and anovulatory menstrual cycles, which have been linked with an increased risk of DTC. ${ }^{22,23}$ However, when examined by age, the elevated risk associated with later age of menarche has largely been found among women older than 45 years, whereas the risk for irregular cycles has been observed more in younger women. ${ }^{20}$

Thyroid volume and thyroid stimulating hormone (TSH) levels vary across the menstrual cycle. However, it is still not clear how these changes relate to thyroid carcinogenesis. ${ }^{24,25}$ Increased thyroid volume has been associated with later age of menarche and decreased progesterone levels in adolescent girls. ${ }^{20}$ Irregular cycles are associated with an increase in the length of the follicular phase of the cycle, and a progesterone deficit is related to the lack of a normal progesterone surge occurring during the luteal phase. ${ }^{20}$

In addition, a relationship between anthropometric factors (height, weight, body fat) and thyroid cancer risk has been suggested, as thyroid hormone is crucial to the development of several body tissues. A pooled analysis of case-control studies conducted prior to 1998 on this topic showed a weak positive association between thyroid cancer and height, in women, with a relative risk (RR) of 1.2, and increased linearly for those who were taller, as compared against shorter females. ${ }^{26}$ Additionally, a self-reported body mass index (BMI) at time of diagnosis was directly related to thyroid cancer risk, with a RR of 1.2 for obese women and, in continuous analysis, a RR of 1.1 for each 5-unit increase in BMI. ${ }^{27}$ Two other studies explored the influence of anthropometric measures. A study conducted in California found no association between thyroid cancer risk and BMI, height, or weight gain, ${ }^{28}$ while a Norwegian study reported an increased risk of thyroid cancer with increasing height and BMI. ${ }^{29}$

Physical activity has also been suggested as an influence on cancer risk, through hormonal, metabolic, and immunologic means. Three studies yielded mixed results when comparing sedentary versus heavy physical occupational activity ${ }^{30,31}$ Another study examined Californian women with PTC, and found that the RR of thyroid cancer, among those who reported regular recreational exercise during the 2 years before diagnosis, was slightly reduced, as compared with those who did not report exercise during the same period. ${ }^{32}$

A study published in 2010 on thyroid cancer and gender disparity could find no clear cause of the disparity in incidence or aggressiveness of DTC between men and women. Dietary and environmental factors did not appear to have significant roles in the gender disparity, nor did common somatic mutations. ${ }^{33}$

A number of prognostic factors for thyroid carcinoma have been identified, including sociodemographic characteristics, such as age and gender, and tumor characteristics, such as histology and stage. ${ }^{34}$ Several studies have shown that the prognosis for DTC is favorable in patients below 40 years of age. DTC in children and adolescents has a low mortality, but a high risk of recurrence. Young patients with large, multifocal tumors that are already metastatic at the time of diagnosis have the highest risk of recurrence. Data from a study by Welch Dinauer et al found a low mortality rate among 137 patients with DTC. However, a significant morbidity was identified, with as many as $45 \%$ of patients with PTC, and $18 \%$ of patients with FTC, having metastases at the time of diagnosis. ${ }^{35}$ Approximately one in six young adults, or up to $35 \%$ of patients diagnosed with thyroid cancer, develop recurrence of their disease, with $90 \%$ recurring within 7 years. Factors associated with the greatest risk of recurrence included disseminated disease at diagnosis, palpable cervical lymph nodes, and multifocal and large (greater than $2 \mathrm{~cm}$ ) tumors. The lowest risk of recurrence was found in patients with unifocal FTC. ${ }^{35}$ 


\section{Current and emerging treatment options}

The initial treatment strategy for DTC includes surgery, radioactive iodine treatment, and thyroid hormone suppression therapy. Recommendations regarding the standard of care in treating thyroid cancer are based on retrospective data. Clinically unrecognized thyroid cancer has been found in up to $36 \%$ of autopsies, which is much greater than the prevalence of the diagnosed cancer. Since up to $35 \%$ of patients have recurrences, most physicians recommend treatment. ${ }^{36}$

Total thyroidectomy is the primary surgery for DTC; lobectomy is only considered when the tumor is small $(<1 \mathrm{~cm})$ and is without evidence of local metastasis. ${ }^{37}$ Total thyroidectomy yields adequate staging and, if clinically appropriate, subsequent therapy is with RAI. Additionally, $30 \%-85 \%$ of patients have multifocal disease, which may not be appreciated until after evaluation of surgical specimens. ${ }^{38}$

The extent of cervical lymphadenectomy remains controversial in the treatment of DTC. Certainly, therapeutic control, or lateral neck lymph node dissections, should be undertaken for biopsy-proven, regionally metastatic, nodal disease. Prophylactic lateral neck dissection is not indicated for DTC. Prophylactic central neck dissection may be undertaken, to treat clinically unapparent disease, in the hope of preventing any future need for re-operative surgery, or to document a pathological node that is in a negative state, in an effort to avoid the need for adjuvant RAI. In many patients, lymph node metastases in the central compartment do not appear abnormal preoperatively, using imaging, or upon inspection during surgery. Therapeutic or prophylactic central compartment dissection can be achieved with low morbidity in experienced hands, and may convert some patients from clinical node negative pathology to pathologic node pathology, thereby upstaging patients aged over 45 from the American Joint Committee on Cancer. ${ }^{37}$ Caution must always be taken during a central neck dissection, to avoid morbidity to structures such as the parathyroid glands and the recurrent laryngeal nerve. ${ }^{39}$

RAI can be administered postoperatively, to ablate remaining normal or malignant thyroid cells, and improve the specificity of future surveillance imaging for detection of recurrent disease. It also allows physicians to monitor serum thyroglobulin, as a marker of disease progression. TSH increases iodine avidity in thyroid cells. Therefore, patients must stop any thyroid hormone therapy, or be treated with recombinant human TSH, in order to drive iodine-131 into remaining cells. ${ }^{36} \mathrm{RAI}$ treatment has not been shown to decrease recurrence rates in low-risk patients, with tumors of less than $1.5 \mathrm{~cm}$ diameter, and does have potential side effects, including damage to salivary glands, bone marrow, and gonads. Therefore, it should be used selectively, in patients who would receive the greatest benefit. ${ }^{36}$

The third component of DTC therapy is thyroid hormone suppression. The goal of suppression therapy is to keep TSH levels low, as several series have shown decreased rates of recurrence and cancer-related mortality with suppression therapy. ${ }^{40}$ The degree of TSH suppression depends on the risk of the cancer, and no evidence has shown that low-risk patients require suppression..$^{38}$ Serum TSH levels should be maintained at levels $<0.1 \mathrm{mU} / \mathrm{L}$ in high-risk patients (stages III and IV), whereas lower-risk patients should be allowed to have their TSH levels rise into the normal range. ${ }^{41}$ Patients with thyroid cancer require lifelong monitoring, with surveillance tests to measure thyroglobulin levels, neck ultrasounds, and iodine-131 total body scans. ${ }^{36}$

Patients with progressive DTC who are not responsive to standard treatment require additional therapy, focusing on local disease control in the neck, as well as management of systemic disease. Revision, or re-operative neck dissection, should be considered if the cancer threatens vital neck structures, and even in the setting of metastatic disease. External beam radiation, to control disease progression in DTC, has been used infrequently, except as a palliative treatment for locally advanced, otherwise unresectable disease.$^{37}$ It remains unknown whether external beam radiation might reduce the risk of cancer recurrence in the neck, following adequate primary surgery or RAI treatment, in patients with aggressive histologic subtypes. ${ }^{37}$

Recently, new agents that target and block intracellular signaling aberrancies in thyroid carcinoma, namely the constitutive activation of the MAPK pathway and vascular endothelial growth factor receptors, have emerged in the treatment of advanced thyroid cancer. Most of the agents are tyrosine kinase inhibitors that have activity against pathways implicated in DTC. New data on the activity of sorafenib and sunitinib in advanced thyroid cancer have led to the inclusion of both drugs on the National Comprehensive Cancer Network (NCCN) Drug and Biologic Compendium. The NCCN Clinical Practice Guidelines in Oncology for Thyroid Carcinoma recommend the use of sorafenib or sunitinib for systemic metastatic disease, when a clinical trial is not available or appropriate. ${ }^{42}$

Sorafenib is an oral tyrosine kinase inhibitor with activity against multiple kinases, including $B R A F$ and $R E T$ 
proto-oncogenes. The drug has shown cytostatic effects in thyroid tumor cell lines, both with and without the presence of $B R A F$ mutations. One study enrolled 55 patients with metastatic, iodine-refractory thyroid cancer (all types). Patients with PTC tumors containing BRAF mutations had a significantly longer progression-free survival (PFS) of 84 weeks, compared with patients with wild-type $B R A F$, who had PFS of 54 weeks. ${ }^{43}$

Sunitinib, like sorafenib, is an oral tyrosine kinase inhibitor with multiple targets, including PDGFR, VEGFR, and $R E T$. In one study, 43 patients with progressive disease, who had failed standard therapy, were enrolled. Of 31 patients with DTC who completed two cycles of sunitinib, 13\% had a partial response, and $68 \%$ had stable disease. In a second study of 15 patients, evaluated at 3 months, one had a partial response and 12 had stable disease. ${ }^{44}$

\section{Conclusion}

The goal of this review was to provide clinicians and researchers with a broad overview of the incidence and survival rates of DTC in the young female population. Recent research has contributed to a better understanding of the molecular and genetic basis of DTC. While anthropometric factors and sex steroid hormones may be risk factors associated with DTC in young females, there is still no clear cause of the disparity in incidence or aggressiveness of DTC between men and women.

In conclusion, targeted therapy now presents new treatment options for patients with advanced DTC, with more recent studies focusing on patients with progressive disease, as these patients have higher morbidity and mortality from their cancers. Randomized controlled studies are currently underway to assess whether these targeted agents improve overall survival.

\section{Disclosure}

The authors report no conflicts of interest in this work.

\section{References}

1. National Cancer Institute. Thyroid cancer treatment $\left(\mathrm{PDQ}^{\circledR}\right)$; cited Feb 2013. Available from: http://www.cancer.gov/cancertopics/pdq/treatment/ thyroid/HealthProfessional/. Accessed October 4, 2013.

2. American Cancer Society. Cancer facts and figures 2013. Available from: http://www.cancer.org/acs/groups/content/@epidemiologysurveilance/ documents/document/acspc-036845.pdf. Accessed October 4, 2013.

3. Waguespack S, Wells S, Ross J, Bleyer A. Chapter 12: Thyroid cancer. In: National Cancer Institute. SEER AYA Monograph. Available from: http://www.seer.cancer.gov/publications/aya/12_thyroid.pdf. Accessed October 4, 2013.

4. Kilfoy BA, Devesa SS, Ward MH, et al. Gender is an age-specific effect modifier for papillary cancers of the thyroid gland. Cancer Epidemiol Biomarkers Prev. 2009;18(4):1092-1100.
5. Davies L, Welch HG. Increasing incidence of thyroid cancer in the United States, 1973-2002. JAMA. 2006;295(18):2164-2167.

6. Chen AY, Jemal A, Ward EM. Increasing incidence of differentiated thyroid cancer in the United States, 1988-2005. Cancer. 2009;115(16): 3801-3807.

7. Surveillance, Epidemiology, and End Results (SEER) Program (www. seer.cancer.gov) Research Data (1973-2010), National Cancer Institute, DCCPS, Surveillance Research Program, Surveillance Systems Branch, released April 2013, based on the November 2012 submission.

8. Ying AK, Huh W, Bottomley S, Evans DB, Waguespack SG. Thyroid cancer in young adults. Semin Oncol. 2009;36(3):258-274.

9. McNally RJ, Blakey K, James PW, Gomez Pozo B, Basta NO, Hale J. Increasing incidence of thyroid cancer in Great Britain, 1976-2005: age-period-cohort analysis. Eur J Epidemiol. 2012;27(8):615-622.

10. Lise M, Franceschi S, Buzzoni C, et al. Changes in the incidence of thyroid cancer between 1991 and 2005 in Italy: a geographical analysis. Thyroid. 2012;22(1):27-34.

11. Sobrinho-Simoes M, Maximo V, Rocha AS, et al. Intragenic mutations in thyroid cancer. Endocrinol Metab Clin North Am. 2008;37(2): 333-362, viii.

12. Nikiforov YE. Thyroid carcinoma: molecular pathways and therapeutic targets. Mod Pathol. 2008;21 Suppl 2:S37-S43.

13. Alberti L, Carniti C, Miranda C, Roccato E, Pierotti MA. RET and NTRK1 proto-oncogenes in human diseases. J Cell Physiol. 2003; 195(2):168-186.

14. Kebebew E. Hereditary non-medullary thyroid cancer. World J Surg. 2008;32(5):678-682.

15. Alsanea $\mathrm{O}$, Wada $\mathrm{N}$, Ain $\mathrm{K}$, et al. Is familial non-medullary thyroid carcinoma more aggressive than sporadic thyroid cancer? A multicenter series. Surgery. 2000;128(6):1043-1050; discussion 1050-1051.

16. Malchoff CD, Malchoff DM. Familial nonmedullary thyroid carcinoma. Semin Surg Oncol. 1999;16(1):16-18.

17. Bleyer A, Barr R, Hayes-Lattin B, Thomas D, Ellis C, Anderson B. The distinctive biology of cancer in adolescents and young adults. Nat Rev Cancer. 2008;8(4):288-298.

18. Vriens MR, Moses W, Weng J, et al. Clinical and molecular features of papillary thyroid cancer in adolescents and young adults. Cancer. 2011;117(2):259-267.

19. Kikuchi S, Perrier ND, Ituarte P, Siperstein AE, Duh QY, Clark OH. Latency period of thyroid neoplasia after radiation exposure. Ann Surg. 2004;239(4):536-543.

20. Horn-Ross PL, Canchola AJ, Ma H, Reynolds P, Bernstein L. Hormonal factors and the risk of papillary thyroid cancer in the California Teachers Study cohort. Cancer Epidemiol Biomarkers Prev. 2011;20(8): 1751-1759.

21. Sakoda LC, Horn-Ross PL. Reproductive and menstrual history and papillary thyroid cancer risk: the San Francisco Bay Area thyroid cancer study. Cancer Epidemiol Biomarkers Prev. 2002;11(1):51-57.

22. Negri E, Dal Maso L, Ron E, et al. A pooled analysis of case-control studies of thyroid cancer. II. Menstrual and reproductive factors. Cancer Causes Control. 1999;10(2):143-155.

23. Zivaljevic V, Vlajinac H, Jankovic R, et al. Case-control study of female thyroid cancer - menstrual, reproductive and hormonal factors. Eur $J$ Cancer Prev. 2003;12(1):63-66.

24. De Remigis P, Raggiunti B, Nepa A, Giandonato S, Faraone G, Sensi S. Thyroid volume variation during the menstrual cycle in healthy subjects. Prog Clin Biol Res. 1990;341A:169-173.

25. Schottenfeld D, Fraumeni JF. Cancer Epidemiology and Prevention. 3rd ed. Oxford: Oxford University Press; 2006.

26. Dal Maso L, La Vecchia C, Franceschi S, et al. A pooled analysis of thyroid cancer studies. V. Anthropometric factors. Cancer Causes Control. 2000;11(2):137-144.

27. Dal Maso L, Bosetti C, La Vecchia C, Franceschi S. Risk factors for thyroid cancer: an epidemiological review focused on nutritional factors. Cancer Causes Control. 2009;20(1):75-86.

28. Iribarren C, Haselkorn T, Tekawa IS, Friedman GD. Cohort study of thyroid cancer in a San Francisco Bay area population. Int J Cancer. 2001;93(5):745-750. 
29. Akslen LA, Nilssen S, Kvale G. Reproductive factors and risk of thyroid cancer. A prospective study of 63,090 women from Norway. Br J Cancer. 1992;65:772-774.

30. Wong EY, Ray R, Gao DL, et al. Reproductive history, occupational exposures, and thyroid cancer risk among women textile workers in Shanghai, China. Int Arch Occup Environ Health. 2006;79(3): 251-258.

31. Wingren G, Hatschek T, Axelson O. Determinants of papillary cancer of the thyroid. Am J Epidemiol. 1993;138(7):482-491.

32. Rossing MA, Remler R, Voigt LF, Wicklund KG, Daling JR. Recreational physical activity and risk of papillary thyroid cancer (United States). Cancer Causes Control. 2001;12(10):881-885.

33. Rahbari R, Zhang L, Kebebew E. Thyroid cancer gender disparity. Future Oncol. 2010;6(11):1771-1779.

34. Gilliland FD, Hunt WC, Morris DM, Key CR. Prognostic factors for thyroid carcinoma. A population-based study of 15,698 cases from the Surveillance, Epidemiology and End Results (SEER) program 1973-1991. Cancer. 1997;79(3):564-573.

35. Welch Dinauer CA, Tuttle RM, Robie DK, et al. Clinical features associated with metastasis and recurrence of differentiated thyroid cancer in children, adolescents and young adults. Clin Endocrinol. 1998;49(5): 619-628.

36. Brown RL, de Souza JA, Cohen EE. Thyroid cancer: burden of illness and management of disease. J Cancer. 2011;2:193-199.
37. Cooper DS, Doherty GM, Bryan RH, et al. Revised American thyroid association management guideline for patients with thyroid nodules and differentiated thyroid cancer. Thyroid. 2009;19(11):1167-1214.

38. Sosa JA, Udelsman R. Total thyroidectomy for differentiated thyroid cancer. J Surg Oncol. 2006;94(8):701-707.

39. White ML, Gauger PG, Doherty GM. Central lymph node dissection in differentiated thyroid cancer. World J Surg. 2007;5:895-904.

40. Biondi B, Filetti S, Schlumberger M. Thyroid-hormone therapy and thyroid cancer: a reassessment. Nat Clin Pract Endocrinol Metab. 2005;1(1):32-40.

41. Cooper, DS. TSH: suppressive therapy: An overview of long-term clinical consequences. Hormones. 2010;9(1):57-59.

42. National Comprehensive Cancer Network. Thyroid carcinoma; cited Feb 2013. Available from: http://www.nccn.org/professionals/physician_gls/ PDF/thyroid.pdf. Accessed October 4, 2013.

43. Ahmed M, Riddell A, Whittaker S, et al. Preliminary results of an open labeled phase 2 study evaluating the safety and efficacy of sorafenib in metastatic advanced thyroid cancer. J Clin Oncol. 2008;26:a6060.

44. Ravaud A, de la Fouchardière C, Courbon F, et al. Sunitinib in patients with refractory advanced thyroid cancer: the THYSU phase II trial. J Clin Oncol. 2008;26(15S):6058.
Clinical Oncology in Adolescents and Young Adults

\section{Publish your work in this journal}

Clinical Oncology in Adolescents and Young Adults is an international, peer-reviewed, open access journal publishing original research, reports, editorials, reviews and commentaries on all aspects of epidemiology, diagnosis and treatment of cancers in adolescents and young adults. The manuscript management system is completely

\section{Dovepress}

online and includes a very quick and fair peer-review system. Visit http://www.dovepress.com/testimonials.php to read real quotes from published authors.

\footnotetext{
Submit your manuscript here: http://www.dovepress.com/clinical-oncology-in-adolescents-and-young-adults-journal
} 